\title{
A Weak Field EPR Study of TANOL in Water and Water-Oil Using Dynamic Nuclear Polarization
}

\author{
N. Horasan, M. M. Sünnetçioğlu, R. Sungur, and G. Bingöl \\ Magnetic Resonance Laboratory, Department of Physics Engineering, Hacettepe University, \\ 06532 Beytepe-Ankara, Türkiye
}

Z. Naturforsch. 52a, 485-489 (1997); received January 29, 1997

Solutions of 4-hydroxy-TEMPO(TANOL) in water and water-soyabean oil were investigated in the concentration range $0.1 \mathrm{mM}-10 \mathrm{mM}$. Dynamic nuclear polarization (DNP) and electronic relaxation time $T_{1 \mathrm{e}}$ measurements were performed at each well resolved hyperfine line. In the TANOL/water-soyabean oil solutions, the effect of the presence of soyabean oil was an increase in the measured relaxation rates and a decrease in the observed enhancements. In addition, the observed enhancements diminished in time. For all of the samples, the relaxation rates decreased as the frequency of the transition increased.

Key words: DNP, EPR, Nitroxides, Electronic relaxation times, Water-Oil.

\section{Introduction}

In recent years, dynamic nuclear polarization (DNP) studies and relaxation rate measurements of nitroxides at low fields gained importance again due to biological applications of nitroxides. These studies range in the $6.8-13.0 \mathrm{mT}$ region [1-6]. To our knowledge there are very few studies at lower fields [2]. Therefore we think that our results, obtained at $1.53 \mathrm{mT}$, will provide complementary information to other studies performed at higher fields.

In this study the nitroxide spin probe TANOL was investigated in three solutions: water, soyabean oil and water-soyabean oil. Using double resonance technique, EPR spectra were recorded and DNP values and electronic relaxation times were measured.

\section{Theory}

In cases where the sample contains both nuclei and unpaired electrons, DNP is a well known double resonance technique to enhance nuclear signals [7-9]. Following the partial saturation of electronic transitions, the cross-relaxation processes between unpaired electrons and solvent nuclei cause an enhancement in

Reprint requests to Prof. R. Sungur, Fax: 010903122352550 . the nuclear signal. The observed enhancement is given as

$$
G(P)=\frac{P_{z}-P_{0}}{P_{0}}=F_{i j} s_{i j},
$$

where $P_{z}$ and $P_{0}$ are the nuclear polarization with and without EPR irradiation, $s_{i j}$ is the saturation for electronic transitions and $F_{i j}$ the enhancement factor for the $i j$ th transition, which is given by

$$
F_{i j}=\varrho f\left(\omega_{i j} / \omega_{k}\right) .
$$

Here $\varrho$ is the electron-nuclear coupling parameter, $f$ gives the ratio of the free radical induced solvent nuclear relaxation rate to the total solvent nuclear relaxation rate, and $\omega_{i j}$ and $\omega_{k}$ are the resonance frequencies for electronic and nuclear transitions.

As a result of the interaction of the nitrogen nucleus with the unpaired electron, EPR spectra of nitroxides at $1.53 \mathrm{mT}$ consist of six well resolved hyperfine lines [10]. This covers a frequency range from 5 to $120 \mathrm{MHz}$. Therefore EPR spectra are recorded by keeping the field amplitude constant and changing the EPR frequency within this range. In the low field EPR spectra of nitroxides for the transition at about $43 \mathrm{MHz}$, the polarization $P_{z}$ is positive, i.e. it is in the direction of the pure nuclear polarization $P_{0}$ (Figure 1). Whereas at all the other transitions the number of nuclear spins at higher energy level is in excess of the lower energy level, at this transition the situation is reverse and the nuclear spin system absorbs radiation $[11,12]$. 


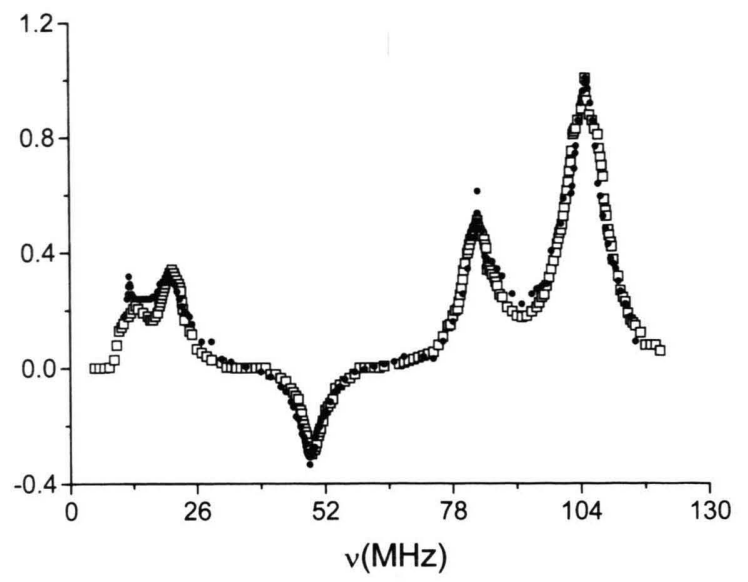

Fig. 1. EPR spectra of TANOL/water $(10 \mathrm{mM})$ solutions; - not degassed, $\square$ degassed.

After the saturation experiments at each resonance line, electronic relaxation times $T_{1 \mathrm{e}}$ were calculated from $[12,13]$

$$
T_{1 \mathrm{e}}^{i j}=\frac{\left|\left(P_{z}-P_{0}\right) / P_{0}\right|_{\text {low power }}}{F_{i j} h\left(\omega_{i j}\right)} \frac{1}{\pi \gamma^{2} B_{1 \mathrm{e}}^{2} g\left(\omega-\omega_{i j}\right)} .
$$

Here $B_{1 \mathrm{e}}$ is the rf field amplitude on the sample, $g\left(\omega-\omega_{i j}\right)$ is the shape function and $\left|\left(P_{z}-P_{0}\right)\right|$ $\left.P_{0}\right|_{\text {low power }}$ is the observed enhancement obtained at low values of $B_{1 \mathrm{e}} \cdot F_{i j} h\left(\omega_{i j}\right)$ is the ultimate enhancement, i.e. the saturation value of the observed enhancement. Because of the respective proportionality between $s_{i j}, B_{1 \mathrm{e}}^{2}$ and the square of the voltage at the EPR coil $\left(V_{\mathrm{e}}^{2}\right)$, the graphs of $G(P)^{-1}$ against $V_{\mathrm{e}}^{2}$ give a straight line and from the extrapolation of this line to infinite power, $F_{i j} h\left(\omega_{i j}\right)$ values can be deduced.

\section{Experimental}

Measurements were performed with a double resonance spectrometer working at $1.53 \mathrm{mT}$. The proton resonance frequency is $65 \mathrm{kHz}$, the EPR frequency can be varied between 5 and $120 \mathrm{MHz}$.

Solutions of the TANOL free radical $(2,2,6,6-\mathrm{Te}-$ tramethylpiperidinol-4-oxyl-1) in water, water-soyabean oil and in soyabean oil were prepared in the $0.1 \mathrm{mM}-10 \mathrm{mM}$ concentration range and, when necessary, degassed using freeze-thaw-pump technique. Commercial oils were used in the experiments. The soyabean oil includes antioxidant material $(0.2 \mathrm{mM})$. Measurements were performed at room temperature.

\section{Results and Discussion}

In Fig. 1 the EPR spectra of $10 \mathrm{mM}$ TANOL/water solutions with and without degassing were compared. For degassed samples at 21.49 and $83.00 \mathrm{MHz}$ only a slight decrease in the line widths and an increase in the electronic relaxation rates were observed (Figure $2 \mathrm{a}$ ). If the enhancement factors of these two samples are considered, higher enhancement factors were obtained for deoxygenated samples at all frequencies (Figure 2b).

The concentration dependent investigation of TANOL/water solutions in the $0.1-10 \mathrm{mM}$ range indicated an increase in the ultimate enhancements, as expected (Figure $3 \mathrm{a}$ ). For the relaxation rates an inspection of Fig. $3 \mathrm{~b}$ indicates that there is an increase in the relaxation rates when the concentration changed from $1 \mathrm{mM}$ to $10 \mathrm{mM}$. However, the measured relaxation rates for $1 \mathrm{mM}$ and $0.1 \mathrm{mM}$ samples were close to each other. The results obtained for TANOL/water solutions were also compared with the

a)

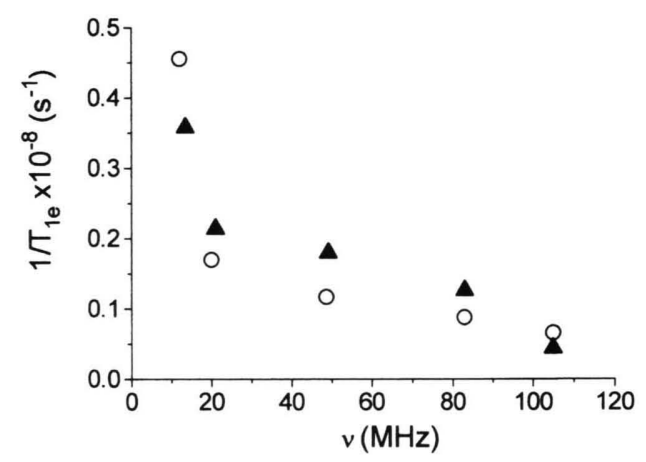

b)

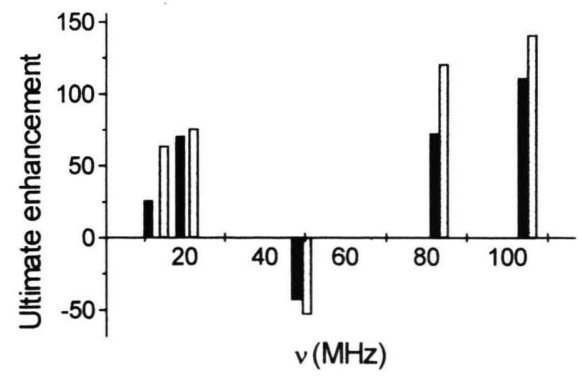

Fig. 2. a) Relaxation rates of TANOL/water $(10 \mathrm{mM})$ solutions; $\circ$ not degassed, $\Delta$ degassed. b) Ultimate enhancements of TANOL/water $(10 \mathrm{mM})$ solutions; not degassed, 和 degassed. 
a)

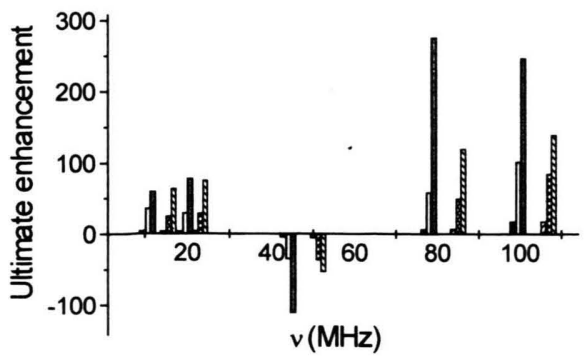

b)

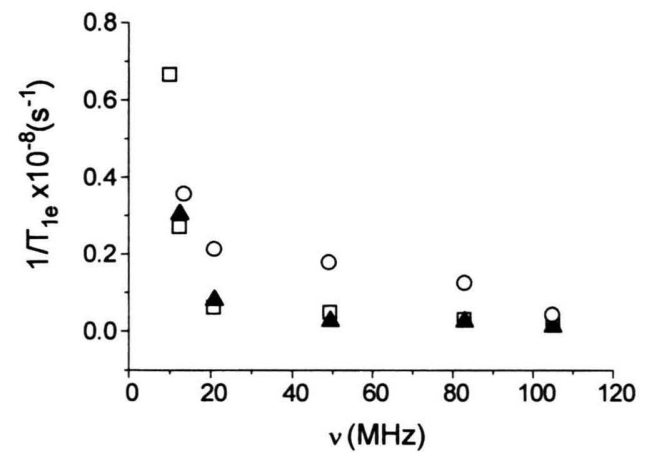

Fig. 3. a) Ultimate enhancements of TANOL/ethyl alcohol solutions; $\square .1 \mathrm{mM}, \square 1 \mathrm{mM}, 10 \mathrm{mM}$, and TANOL/water solutions; $1 \mathrm{IIV} 0.1 \mathrm{mM}$, $1 \mathrm{mM}, \mathrm{WIT}$ $10 \mathrm{mM}$. b) Relaxation rates of TANOL/water $\circ 10 \mathrm{mM}$, $1 \mathrm{mM}, \Delta 0.1 \mathrm{mM}$.

results obtained for TANOL/ethyl alcohol solutions in a previous study of our group [14]. For these samples the ultimate enhancements were very close to each other at $0.1 \mathrm{mM}$ and $1 \mathrm{mM}$ concentrations, but for $10 \mathrm{mM}$ concentration the ultimate enhancements were two times larger for ethyl alcohol solutions for the transitions from $45 \mathrm{MHz}$ to $100 \mathrm{MHz}$ (Figure 3a). The reason of this difference might be the higher degree of hydrogen-bridge formation for water protons with increasing concentration $[15,16]$.

A consideration of Fig. $3 \mathrm{~b}$ indicates a transitionfrequency dependent order of relaxation rates for these samples at all investigated concentrations, however, this dependence is more efficient for higher concentration $(10 \mathrm{mM})$.

Lipids and water are fundamental structural materials of biological samples. Therefore an investigation was performed to understand their DNP at low field.

A solution of TANOL in soyabean oil was prepared at $1 \mathrm{mM}$ concentration but no enhancement was ob- served. However, the spectra of the same sample at the $0.3 \mathrm{~T}$ has given a very good signal to noise ratio. Another sample was prepared in olive oil at again $1 \mathrm{mM}$ concentration. Although the viscosity of olive oil is higher than that of soyabean oil, for olive oil we obtained a slight enhancement at room temperature. As the temperature of the sample was increased slightly, the observed enhancement increased as well. This indicates that the viscosity is not the only reason which prevents the cross polarization between electrons and protons in soyabean oil.

Prior to the relaxation measurements with degassed samples, some enhancement observations were performed using the following samples:

I. $5 \mathrm{ml}$ water in which $2 \mathrm{mM}$ TANOL was dissolved and $5 \mathrm{ml}$ soyabean oil added.

II. $5 \mathrm{ml}$ TANOL/soyabean oil and $5 \mathrm{ml}$ water added.

III. $5 \mathrm{ml} \mathrm{TANOL/soyabean} \mathrm{oil} \mathrm{at} 1 \mathrm{mM}$ concentration and $5 \mathrm{ml} \mathrm{TANOL/water} \mathrm{at} 1 \mathrm{mM}$ concentration.

For sample I, the observed enhancement decreased slightly upon addition of soyabean oil. For sample II the observed enhancement increased with addition of water. This increase was relatively large in comparison with the decrease observed for sample I. For Sample I, the observed enhancements were higher than for sample III. After degassing sample I and III, the measurements were repeated, and again the enhancement for sample I was higher.

$T_{1 \mathrm{e}}$ measurements were performed for sample III at all resonance frequencies. For this sample there were no changes relative to TANOL/water ( $1 \mathrm{mM})$, but for all frequencies the electronic relaxation rates were larger for the TANOL/water-soyabean oil (Figure $4 \mathrm{a}$ ). The results obtained were an indication of the partition of TANOL molecules in water and soyabean oil environments. In a separate study of our group at $0.3 \mathrm{~T}$, some model experiments were performed to study the motion of TANOL molecules in water-oil medium [17]. From these model experiments, the transition of TANOL molecules from water to oil was observed. In solutions containing water and oil there exist two way transitions of TANOL molecules. Since TANOL is a hydrophilic spin probe, the transition rate of TANOL molecules from oil to water is expected to be higher than that of from water to oil. These transitions cause an increase in molecular mo- 
a)

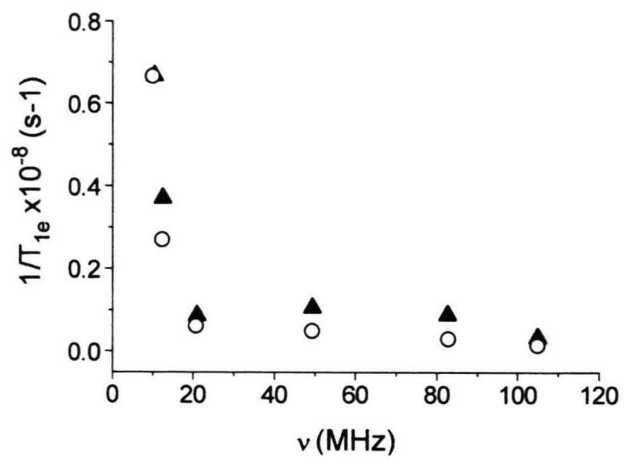

b)

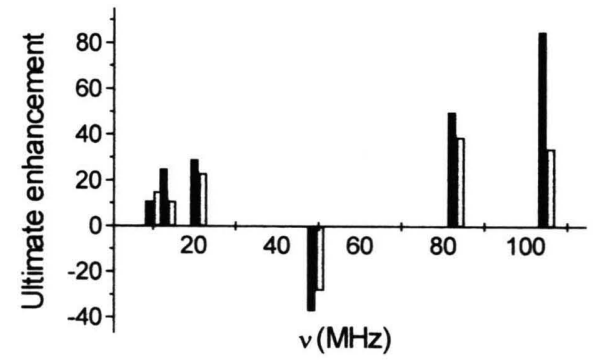

Fig. 4. a) Relaxation rates of (1 mM); TANOL/water (o) and TANOL/water-soyabean oil ( $\mathbf{\Delta})$ samples. b) Ultimate enhancements of $(1 \mathrm{mM})$; TANOL/water ( $)$ and TANOL/ water-soyabean oil ( samples.

tions and consequently an increase in the relaxation rates relative to the TANOL/water solution.

Considering the ultimate enhancements for these two samples, there was an important decrease for the TANOL/water-soyabean oil sample (Figure 4 b). In addition to that, the observed enhancements of the TANOL/water-soyabean oil sample decrease slowly in time. To study this behavior, starting from freshly prepared samples, the measurements were repeated and, depending on the preparation time of the samples, the decays were followed for four months, cf. Figure 5. The measurements were performed with both degassed and not degassed samples, and the re-

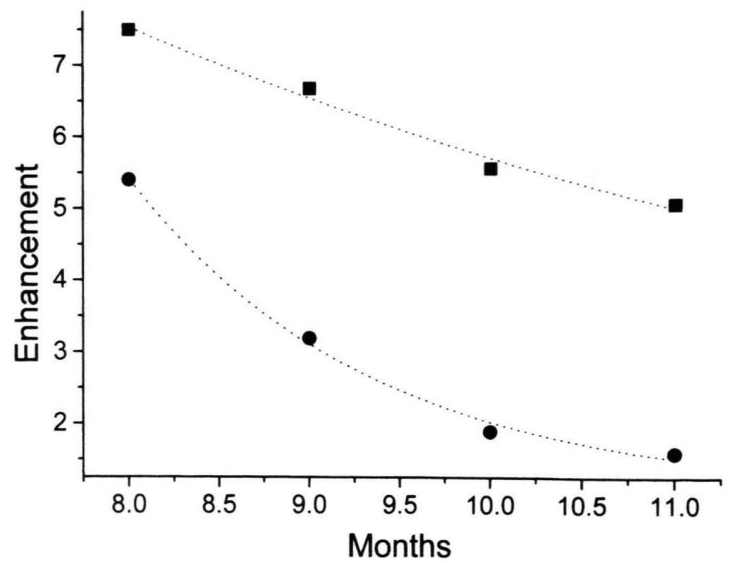

Fig. 5. Enhancements of TANOL/water-oil $10 \mathrm{mM}$ solutions prepared on August 12, 1996 in vacuum and then observed for four months ( $)$; TANOL/water-oil $10 \mathrm{mM}$ solutions prepared on July 12, 1994 in vacuum opened to air in March 1996, then degassed again on August 12, 1996 and observed for four months $(\bullet)$.

sults indicate a slight increase in the observed enhancements after the degassing procedure. The following decay in time makes us think that there is a slow process of complex formation between nitroxides and oil molecules. After the slow decay, i.e. approximately four months after the measurements, the samples were opened to air again and the measurements were repeated. Interestingly, again a slight increase in the observed enhancements was seen.

To finish with, this study gave us some information about the DNP of oils and oil-water solutions in weak magnetic fields. However, to get further information about these solutions, a temperature dependent study is necessary.

\section{Acknowledgements}

We would like to thank TÜBİTAK (The Scientific and Technical Research Council of Turkey) for the financial support of the project. 
[1] D. J. Lurie, J. M. S. Hutchison, L. H. Bell, I. Nicholson, D. M. Bussell, and J. R. Mallard, J. Magn. Reson. 84, 431 (1989).

[2] D. J. Lurie, I. Nicholson, and J. R. Mallard, J. Magn. Reson. 94, 197 (1991).

[3] D. J. Lurie, I. Nicholson, and J. R. Mallard, J. Magn. Reson. 95, 405 (1991).

[4] D. Grucker, Magn. Reson. Med. 14, 140 (1990).

[5] D. Grucker and J. Chambron, J. Magn. Reson. 94, 631 (1991).

[6] D. Grucker, J. Guiberteau, B. Eclancher, J. Chambron, R. Chiarelli, A Rassat, G. Subra, and B. Galley, J. Magn. Reson. B 106, 101 (1995).

[7] K. H. Hausser and D. Stehlik, Adv. Magn. Reson. I, 79 (1968).

[8] J. Haupt and W. Müller-Warmuth, Z. Naturforsch. 17a, 1011 (1962).
[9] W. Müller-Warmuth and K. Meise-Gresch, Adv. Magn. Reson. I, 1 (1983).

[10] M. Sünnetçioğlu and G. Bingöl, Phys. Chem. Liq. 26, 47 (1983).

[11] W. Müller-Warmuth, Z. Naturforsch. 15a, 927 (1960).

[12] M. Sünnetçioğlu, G. Bingöl, and R. Sungur, Z. Naturforsch. 46 a, 976 (1991).

[13] W. Müller-Warmuth, E. Öztekin, R. Vilhjalmsson, and A. Yalçıner, Z. Naturforsch. 25a, 1688 (1970).

[14] R. Sungur, Doğa Tr. J. Physics 15, 63 (1991).

[15] K. Meise, W. Müller-Warmuth und H. W. Nientiedt, Ber. Bunsenges. Phys. Chem. 80, 584 (1976).

[16] Y. Y. Lim and R. S. Drago, Amer. Chem. Soc. 93, 891 (1971).

[17] M. Sünnetçioğlu, D. Dadaylı, R. Sungur, and G. Bingöl, J. Plant Physiology (in Press). 